three are on the sediments of the French continental shelf, one on sedimentation in the English Channel, and the otber on the geology of the 'Iles Atlantides'. A paper by B. Brajnikov on the origin of the alluvial deposits of the Seine estuary is followed by a series of three by Prof. A. Cailleux, of which one discusses eriteria for distinguishing between marine and fluviatile gravels. Dr. Claude Francis-Bœuf, who is the author of five of the remaining papers, is well known for papers already published on the processes involved in estuarial sedimentation-a topic of great present-day importance. He discusses the physicochemical factors of estuarial waters in connexion with the tropisms which affect eel migrations; sedimentation in estuaries; the oxygen content of fluviomarine muds, and the production and consumption of oxygen in the topmost surface layer of the latter. The last paper, by V. Romanovsky, is on the elasticity of agar-agar gels. All the papers included are reprints from various publications; the practice of issuing annual fascicules of reprints in special branches of study is very valuable to those directly interested.

\section{International Committee on Nomenclature of Ocean Bottom Features}

THE International Union of Geodesy and Geophysics re-establi hed, at its Oslo meeting in August 1948, an Inteyational Committee on the Nomenclature of Occan Bottom Features under the chairmanship of Dr. J. D. H. Wiseman, British Museum (Natural History). The other members of this Committee gle: Vice-Admiral J. D. Nares (secretary), Internotional Hydrographic Bureau, Monaco; Dr. K. C. Emery, United States; Prof. H. H. Hess, United States; Prof. Hans Pettersson, Sweden; and Prof. Ph. Kuenen, Holland. The terms of reference of the Committee are: "To endeavour to establish in co-operation with the chart-making authorities, mechanisms for the International agreement on the nomenclature of submarine topographical features, as well as considering methods of presentation of marine topographical data on bathymetrical charts".

In order to facilitate the work of this International Committee, a British National Committee has been established under the chairmanship of Dr. J. D. H. Wiseman, with the following members: Mr. C. D. Ovey (secretary), British Museum (Natural History); Dr. J. N. Carruthers, Admiralty ; Dr. L. H. N. Cooper, Marine Biological Association of Great Britain, Plymouth ; Mr. H. F. P. Herdman, "Discovery" Investigations; Prof. W. B. R. King, Sedgwick Museum, Cambridge ; Lieut.-Colonel R. B. Seymour Sewell, Zoological Laboratory, Cambridge ; and Mr. J. A. Steers, president of St. Catharine's College, Cambridge. Early consideration will be given by this Committee to the various physiographical features found at the bottom of the oceans, and at a later stage to nomenclature and the presentation of data on bathymetrical charts. The British Committee would welcome and carefully consider any individual contributions or suggestion, which should be addressed to its secretary, Mr. C. D. Ovey, British Museum (Natupal History), Cromwell Road, London, S.W.7. ofse

\section{Maternal Mortalfyoin India}

INQUIRIES into the causes of maternal mortality in Bombay, Volcutta, Delhi and Madras show that the datavelished in the reports of public health depart tnents are unreliable and do not give an accurate pictlue of the real situation. These inquiries have been collated by Dr. S. Pandit in a report of the Indian Research Fund Association (No. 17; June 1948), and show that figures obtained by special investigations are considerably in excess of the numbers recorded in the public health reports. According to the reports of the executive health officer of Bombay, for example, the maternal mortality-rate for the year 1937 was 4.4 per 1,000 live births, whereas the rate determined by Dr. J. Jhirad for the same period was 13.5 per 1,000 live births. A clearer picture of the incidence of maternal mortality and of the causes responsible for it could be obtained only when a better system of recording all vital occurrences and of certification of the causes of death become widely established throughout India.

A statistical review of the figures collected during the investigations emphasizes the need for developing health services for prenatal care, adequate domiciliary and institutional midwifery services and close cooperation among the different agencies responsible for them. The reports recommend provision of facilities for institutional treatment for abnormal midwifery and puerperal sepsis cases. It is suggested that medical men and midwives in maternity services should have knowledge of preventive aspects of maternal care and, wherever possible, services of health visitors should be employed for educational and follow-up work. As anæmia forms one of the main causes of maternal deaths in India, its diagnosis and early treatment during pregnancy is of vital importance, and special attention should be paid to this condition. To improve the maternal health programme a service providing correct information on maternal deaths should be muintained and research into all aspects of maternal health should be con. ducted.

\section{Fertility of Scottish Women}

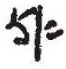

THE widely held belief that decline in fertility among women is dif equ related to the degree of urbanization which $b$ as taken place in a community is not borne oythy investigations which have been made by R. Ka Barclay and W. O. Kermack (Proc. Roy. Soc. Edrn., Section B, 43, Part 11, No. 9). Surveyle the trends of fertility in various sections of the poptation of Scotland from 1860 onwards, they ga $\mathrm{e}$ special attention to the comparison of urban and rural areas. Difficulties in assembling the statistics arose because of the alterations introduced from time to time in the basis of classification used by the Registrar-General ; but these were overcome in various ways. The areas investigated were the four chief cities, Glasgow, Edinburgh, Dundee and Aberdeen, and two groups of counties, one typical of the Highlands (Sutherland, Ross and Cromarty, Inverness and Nairn), and the other typical of the Borders (Peebles, Selkirk, Roxburgh and Berwick).

The results show that the fall in fertility in Scotland set in at about the same time in both urban and rural areas and, broadly speaking, the trends have run closely parallel in these two sections of the community. The fall in the urban section was neither earlier nor more rapid than that in the rural section. Other interesting findings are that the trend of legitimate fertility in the Border group of four counties contrasts strikingly with the trend in the Highland group, the fall in fertility in the former having set in earlier and proceeded more rapidly, while the fall in legitimate fertility in Aberdeen appears to have set in about twenty years later than in the other three large cities of Scotland. 